\title{
Latex allergen exposure increases exhaled nitric oxide in symptomatic healthcare
}

\section{workers}

\author{
X. Baur and L. Barbinova
}

ABSTRACT: The objective of this study was to investigate the clinical and diagnostic impact of baseline exhaled nitric oxide (eNO) levels and latex allergen-induced eNO changes in different healthcare worker groups.

Healthcare workers, 31 latex-sensitised and 14 nonsensitised, underwent occupational-type challenge tests with powdered allergenic latex gloves.

Sensitised as well as nonsensitised healthcare workers developed a significant eNO increase $1 \mathrm{~h}$ after challenge. Conversely, only latex-sensitised employees showed a significant eNO increase $22 \mathrm{~h}$ after challenge, which showed a significant relationship with bronchial obstruction (specific airway resistance changes). However, there was no difference in either baseline eNO level or eNO increase after $22 \mathrm{~h}$ between asthmatic $(n=13)$ and rhinitic only $(n=20)$ responders. The specificity and sensitivity of a $50 \%$ eNO increase after $22 \mathrm{~h}$ in responders were 100 and $56 \%$, respectively.

These results support the assumption that the whole respiratory tract is involved in a combined allergic rhinitis and asthma syndrome. Smoking healthcare workers showed reduced baseline exhaled nitric oxide levels, but, as shown for the first time, an allergen-induced exhaled nitric oxide increase comparable to that of nonsmokers. Corticosteroid therapy inhibited the allergeninduced exhaled nitric oxide change but not the clinical response in the challenge test. These findings suggest that cigarette smoke and corticosteroids initiate distinct molecular mechanisms influencing nitric oxide concentrations in the airways.

KEYWORDS: Allergy, bronchial asthma, latex, nitric oxide

xhaled nitric oxide (eNO) has been described as a marker of allergic airway inflammation in both rhinitic and asthmatic subjects [1-7]. eNO levels may be elevated in patients before asthmatic symptoms develop [8, 9]. HENRIKSEN et al. [8] and GRATZIOU et al. [9] observed a seasonal rise in eNO levels in pollensensitised subjects with and without rhinitic and/or asthmatic symptoms, with a tendency towards increased concentrations in symptomatic subjects.

Despite the considerable number of publications and results indicating relations between baseline eNO level and/or eNO changes on the one hand and symptoms [9-11], bronchial hyperresponsiveness $[12,13]$ and inflammatory parameters of the airways [14] on the other, the clinical role of eNO measurements has not been exactly defined. Moreover, the relation between eNO levels and eNO changes following laboratory allergen challenge has so far rarely been compared between subjects with rhinitic and those with asthmatic responses.

The present hypothesis is that allergen-induced eNO increases have a clinical and diagnostic impact. Considering the influence of possible confounding factors such as atopy, smoking and corticosteroid therapy, it was investigated whether, in different patient subgroups, baseline eNO concentrations, as well as eNO changes, are associated with: 1) latex-specific immunoglobulin (Ig) E and skin-prick test responses; and 2) clinical responses to latex allergens of the upper or lower respiratory tract.

\section{METHODS}

Healthcare workers complaining of work-related rhinitis and/or dyspnoea (43 females and five males) were consecutively examined in the outpatient departments of the Research Institute for Occupational Medicine of the Institutions for Statutory Accident Insurance and Prevention

\section{AFFILIATIONS}

Institute of Occupational Medicine University of Hamburg, Hamburg, Germany.

CORRESPONDENCE

$X$. Baur

Zentralinstitut für Arbeitsmedizin

Hamburg

Seewartenstrasse

D-20459 Hamburg

Germany

Fax: 4940428894514

E-mail: baur@uke.uni-hamburg.de

Received

February 182004

Accepted after revision:

August 012004 
(Bochum, Germany) and the Institute of Occupational Medicine (University of Hamburg, Hamburg, Germany) and included in the present study (table 1). They were subjected to skin-prick testing with 19 common allergens (HAL, Düsseldorf, Germany) and a self-made extract of ammoniated latex from Hevea brasiliensis [15], measurement of latex-specific IgE levels using the CAP system (Pharmacia, Uppsala, Sweden) and methacholine challenge testing as previously described [16]. Subjects with an immediate-type skin test response to latex and/or a respective CAP value of $>0.35 \mathrm{kU} \cdot \mathrm{L}^{-1}$ were defined as latex-sensitised. Atopy was defined as $\geqslant 3-\mathrm{mm}$ weal reactions to at least two of the 19 common allergens in the absence of a reaction to saline. All subjects underwent an occupational-type inhalational challenge using: 1) cornstarch-powdered vinyl gloves (placebo); and 2) cornstarch-powdered allergenic latex gloves $(1,000 \mu \mathrm{g}$ allergen $\cdot g$ rubber $^{-1}$ ) as previously described [16, 17]. The challenge was started using one pair of powdered latex gloves, with latex aeroallergen concentrations of $200-350 \mathrm{ng} \cdot \mathrm{m}^{-3}$ for 20 min, and, in a second step, the number of pairs of gloves was increased to 10 , with air concentrations of $\sim 2,500 \mathrm{ng} \cdot \mathrm{m}^{-3}$ for $30 \mathrm{~min}$.

Eleven subjects had been treated with inhaled corticosteroids for $\geqslant 3$ weeks before the challenge tests (3-6 puffs $\cdot$ day $\left.^{-1}\right)$.

Lung function measurements, including methacholine testing, were performed according to European Respiratory Society (ERS) recommendations [18], using a body plethysmograph (Jaeger, Würzburg, Germany) at rest, after exposure to a placebo (powdered vinyl gloves) and following latex challenge (four times at 15-min intervals within the first hour and then 2, 4, 6 and $22 \mathrm{~h}$ after challenge). Lung function measurement was always conducted before eNO measurement. A significant asthmatic response was defined as an increase in specific airway resistance (sRaw) of $100 \%$ of $>2 \mathrm{kPa} \cdot \mathrm{s}^{-1}$ [19]. A rhinitic response was assumed when rhinorrhoea and repeated sneezing occurred. When this reaction was seen after placebo testing, it was interpreted as a nonspecific (irritative) effect, and respective symptoms after latex challenge were considered not to be due to latex in the same individual (four subjects showed such combined nonspecific reactions).

eNO was measured before challenge and $20 \mathrm{~min}$ and 1, 2, 4, 6 and $22 \mathrm{~h}$ after challenge according to ERS recommendations [20] at an expiratory flow rate of $100 \mathrm{~mL} \cdot \mathrm{s}^{-1}$, using a chemiluminescence analyser (CLD 780 TR; Eco Physics, Dürnten, Switzerland) modified for on-line recording of eNO concentrations. The analyser has a sensitivity to NO of $0.1-$ $500 \mathrm{ppb}$ and a response time of $0.5 \mathrm{~s}$. Each measurement consisted of three successive recordings and means were used in all calculations.

The normal eNO concentration determined in 25 healthy nonsmokers with normal lung function parameters (sRaw, forced vital capacity and forced expiratory volume in one second) at an expiratory flow rate of $100 \mathrm{~mL} \cdot \mathrm{s}^{-1}$ was $7.7 \mathrm{ppb}$ (95\% confidence interval 6.4-9.4 ppb).

The Wilcoxon signed-rank test was used to determine the significance of eNO changes following inhalational latex exposure tests. Using the unpaired t-test or Mann-Whitney U-test, eNO levels and lung function data were compared between sensitised and nonsensitised groups as well as between subgroups. Categorical variables were compared using Chi-squared tests. The two-way generalised linear model was used to analyse the effect of smoking and sensitisation on eNO levels.

\section{RESULTS}

Of the 48 subjects, 34 were found to be latex-sensitised ( 34 gave positive skin-prick test results; 32 of these had $\operatorname{IgE}$ directed against latex).

TABLE 1 Demographic and clinical data of whole study group and various subgroups

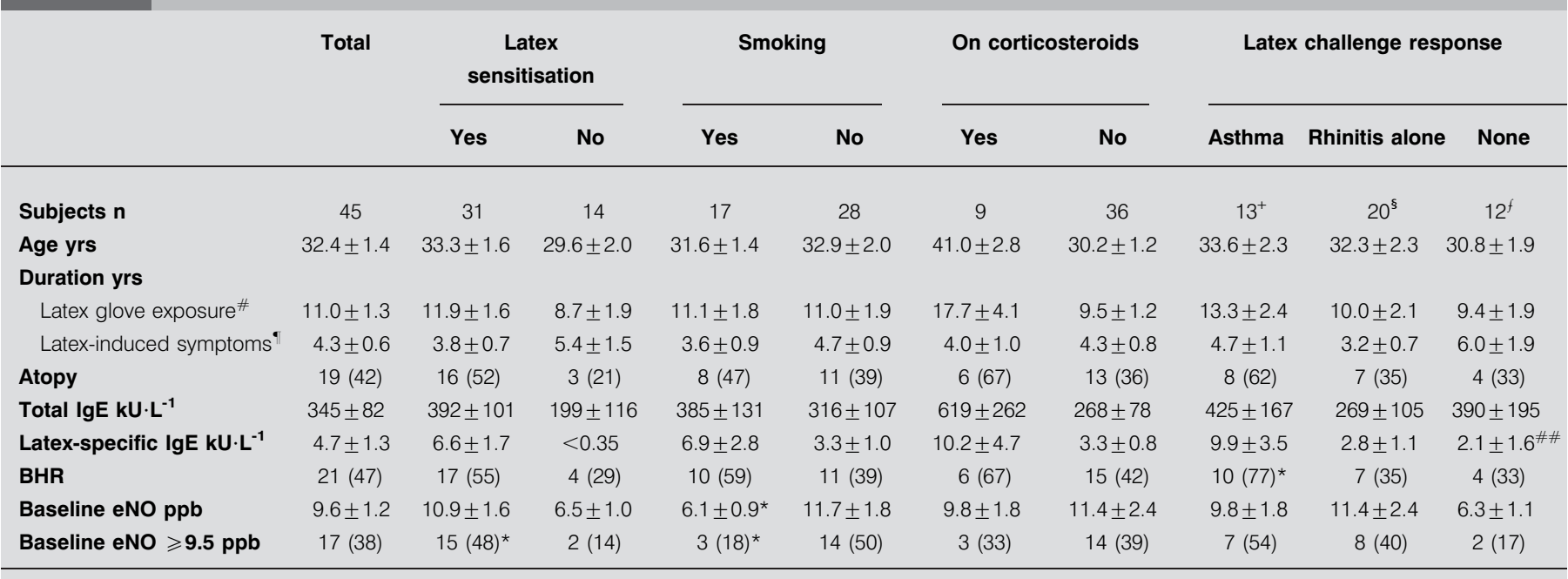

Data are presented as mean \pm SEM or $n$ (\%). Ig: immunoglobulin; BHR: bronchial hyperresponsiveness; eNO: exhaled nitric oxide. ${ }^{\#:}$ occupational allergenic; ${ }^{\text {: }}$ allergic; ${ }^{+}$ all latex sensitised; s: 16 latex sensitised and four nonsensitised; ${ }^{\text {: }}$ two latex sensitised and 10 nonsensitised; \#\#: only two subjects positive. *: significantly different from corresponding reference subgroup(s). 
There were no significant differences between latex-sensitised and nonsensitised healthcare workers, smokers and nonsmokers, and corticosteroid-treated and nontreated subjects with regard to age, duration of latex exposure or latex-induced symptoms, atopy status, total $\operatorname{IgE}$ level and bronchial responsiveness (table 1).

Vinyl gloves (placebo) caused rhinitic symptoms in seven subjects, two of whom were latex-sensitised. Five of these seven subjects (four nonsensitised and one sensitised) also developed rhinitis upon latex glove challenge. These responses were considered nonspecific and not related to latex.

Of the 48 healthcare workers, 16 developed immediate-type asthmatic responses in the occupational-type latex challenge test (fig. 1), which was performed according to a complete test protocol with 10 pairs of latex gloves in 30 subjects and one pair in 18. Three patients exhibiting severe immediate asthmatic reactions and requiring acute therapy (administration of $\beta_{2}$-agonists and corticosteroids) were excluded from the study, i.e. only data from the remaining 45 subjects were analysed. The exclusion of these three subjects did not significantly alter the demographic data and statistical analyses.

Of the 45 remaining patients, 31 showed a rhinitic response upon latex challenge but not upon placebo challenge. Eleven of them showed both asthma and rhinitis and 20 rhinitis alone, the former with strong and the latter with slight $s$ aw increases (fig. 1).

All of the asthmatics, as well as 16 out of the 20 rhinitis only responders, were latex-sensitised. Two sensitised subjects did not respond, i.e. none of the 14 nonsensitised healthcare workers developed asthma, but four of this group showed acute rhinitis upon latex challenge.

In latex-sensitised healthcare workers, baseline eNO concentration was higher than in nonsensitised healthcare workers $(\mathrm{p}=0.1)$, and it was significantly more often above the normal

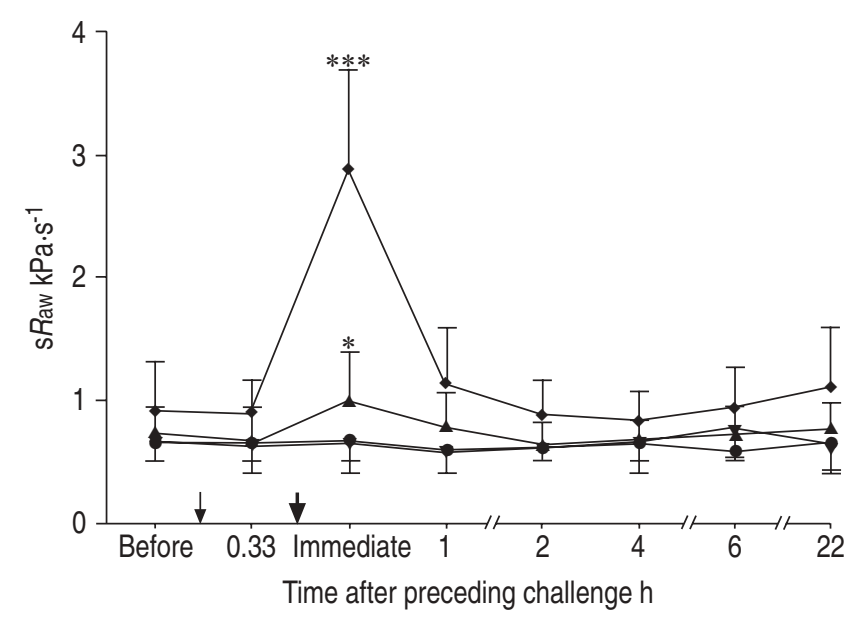

FIGURE 1. Time course of specific airway resistance (sRaw) following placebo (thin vertical arrow) and latex (thick vertical arrow) challenge in latex-sensitised asthmatic responders $(\boldsymbol{\bullet} ;=13)$, latex-sensitised rhinitic responders $(\boldsymbol{\Lambda} ; n=16)$, rhinitic responders without latex sensitisation $(\bullet ; n=4)$ and all nonresponders $(\boldsymbol{\nabla}$; $\mathrm{n}=12)$. Data are presented as mean $\pm \mathrm{SD}$. *: $\mathrm{p}<0.05 ; * \star *: \mathrm{p}<0.001$ versus respective baseline sRaw. range (table 1). Compared to smokers, nonsmokers showed significantly elevated baseline eNO levels $(p=0.03)$. Therefore, smoking status was always considered in further analyses of individual groups and subgroups.

There was no major difference in baseline eNO level between atopic and nonatopic individuals, corticosteroid-treated and -naive subjects, and asthmatic and rhinitic only responders in the latex challenge test. Baseline eNO level was lower in nonresponders irrespective of their smoking status (NS) (table 1).

All nonsmoking subgroups showed nonsignificantly higher baseline eNO levels than smoking subgroups (groups and subgroups considered were: sensitised/nonsensitised, corticosteroid-treated/corticosteroid-naive, and asthmatic/ rhinitic/nonresponders).

Immediately following the placebo test with powdered vinyl gloves, only negligible changes were seen in eNO in sensitised $(0.1 \pm 0.8 \mathrm{ppb})$ and nonsensitised subjects $(0.8 \pm 0.4 \mathrm{ppb})$, as well as in all other subgroups (table 2).

Following latex challenge, the eNO increase was significant in sensitised subjects, revealing a first slight maximum after $1 \mathrm{~h}$. Afterwards, it decreased up to the sixth hour and peaked after 22 h (fig. 2; table 2). At a lower level, nonsensitised healthcare workers showed a similar rise in eNO up to the sixth hour following latex challenge. In contrast to the sensitised group, their eNO level had declined further $22 \mathrm{~h}$ after challenge. Accordingly, there were no significant differences in the time course of eNO change up to the sixth hour following latex challenge between the latex-sensitised and nonsensitised groups. However, significant differences between the two groups were seen after $22 \mathrm{~h}(\mathrm{p}<0.01)$.

At the individual level, an eNO increase of $>50 \%$ from baseline was regarded as the cut-off level of a substantial eNO change after latex challenge in order to categorically differentiate between substantial and nonsubstantial changes. Such an eNO increase of $>50 \%$ occurred $20 \mathrm{~min}$ or $1 \mathrm{~h}$ following latex challenge in 12 out of the 31 (39\%) sensitised healthcare workers as well as in 10 out of the $14(71 \%)$ nonsensitised subjects.

Conversely, with one exception, $22 \mathrm{~h}$ after challenge, only latex-sensitised subjects and responders exhibited an increase of $>50 \%(p<0.05)$ (table 2$)$.

It is noteworthy that percentage eNO increases (relative to the respective baseline value) were very similar within the sensitised group, as well as within the nonsensitised group, irrespective of smoking status (fig. 2). The eNO increase of $>50 \%$ was in $50 \%$ of smoking sensitised healthcare workers and in $47 \%$ of nonsmoking sensitised healthcare workers $22 \mathrm{~h}$ after latex challenge. There were no significant differences in eNO level $22 \mathrm{~h}$ after challenge between smoking and nonsmoking subgroups.

The eNO concentration time courses following latex challenge of asthmatic (fig. 3) and sensitised rhinitic only responders (fig. 4) were very similar, including the parallel courses at lower levels of the smoking subgroups. Furthermore, eNO changes were not associated with atopy. The two nonresponders 


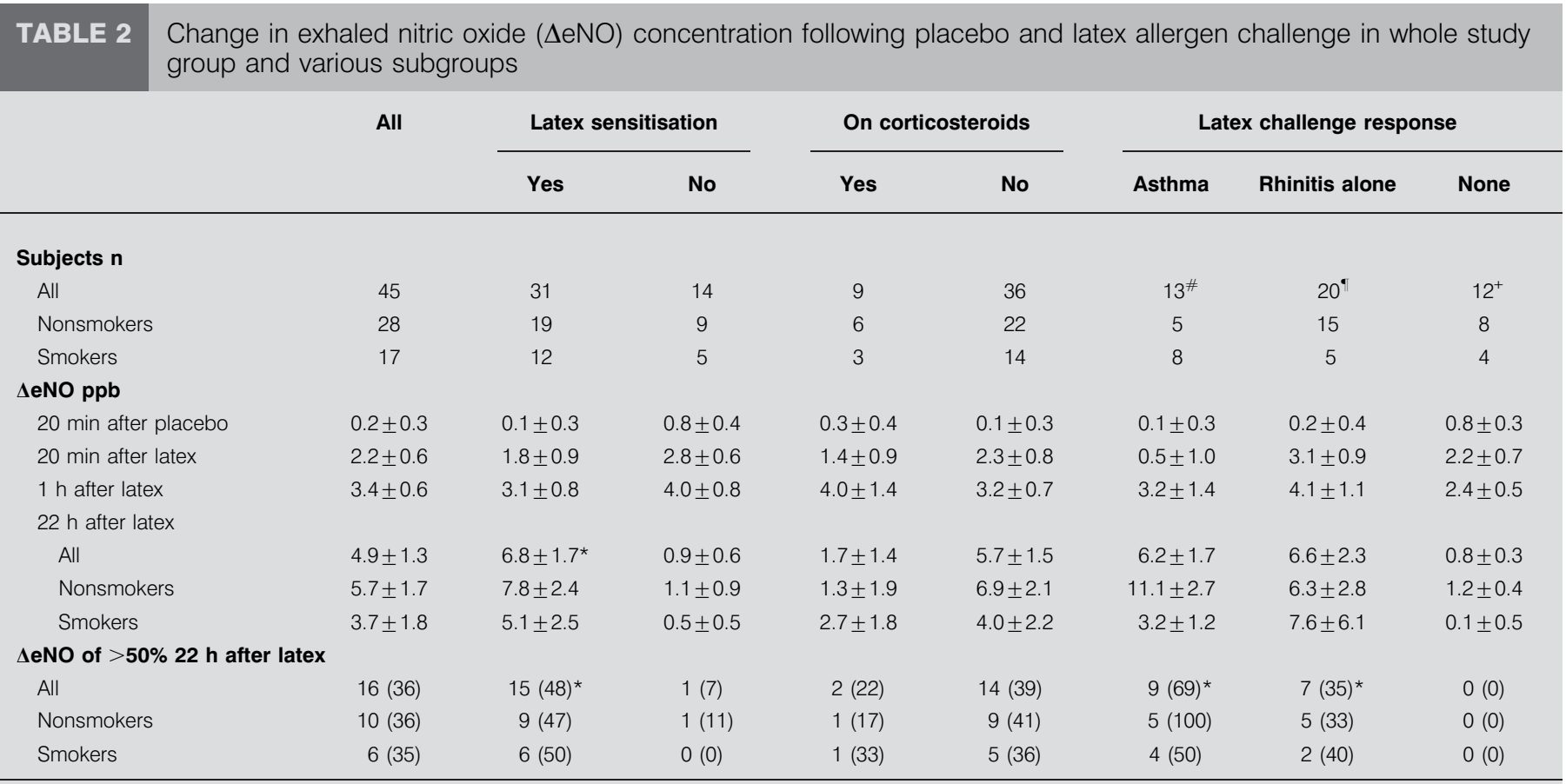

Data are presented as mean \pm SEM or $\mathrm{n}(\%)$. *: all latex sensitised; ": 16 latex sensitised and four nonsensitised; ${ }^{+}$: two latex sensitised and 10 nonsensitised. *: significantly different from corresponding reference subgroup(s).

among the latex-sensitised subjects (both nonsmokers) exhibited low eNO increases of 2.4 and $2.3 \mathrm{ppb}$ after $22 \mathrm{~h}$.

Nonsensitised rhinitic only responders and nonresponders did not show an eNO increase $22 \mathrm{~h}$ following latex challenge (table 2). Both groups exhibited relatively low frequencies of bronchial hyperresponsiveness (33 and 30\%), and all subjects

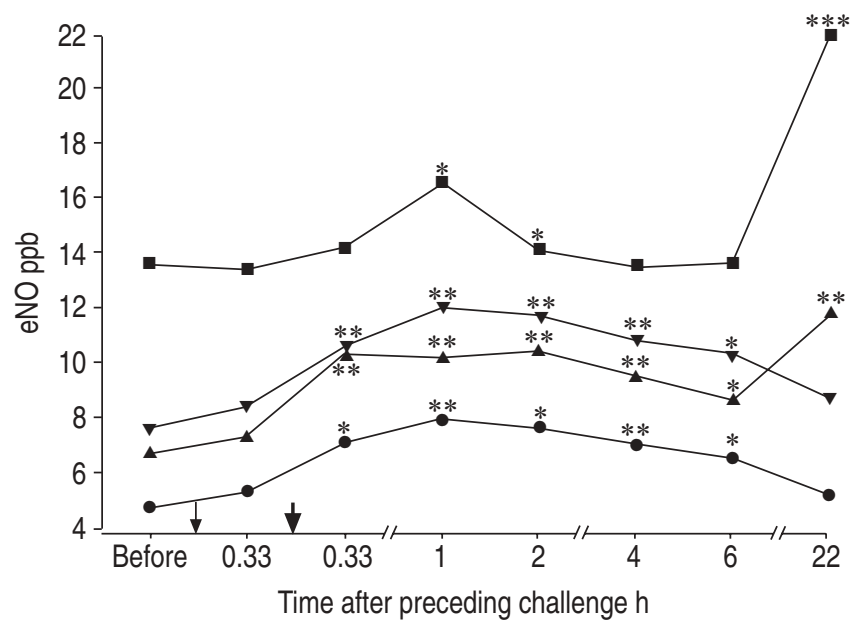

FIGURE 2. Time course of exhaled nitric oxide (eNO) concentration following placebo (thin vertical arrow) and latex (thick vertical arrow) challenge in latexsensitised smokers $(\mathbf{\Lambda} ; \mathrm{n}=12)$ and nonsmokers $(\boldsymbol{\square} ; \mathrm{n}=19)$ and nonsensitised nonsmokers $(\mathbf{\nabla} ; n=9)$ and smokers $(\bullet ; n=5)$. Data are presented as means. The difference in eNO change $22 \mathrm{~h}$ after challenge between sensitised and nonsensitised healthcare workers was significant $(p<0.01)$. *: $p<0.05$; **: $p<0.01 ;{ }^{* * *}: p<0.001$ versus respective baseline eNO. in the former group were nonatopic and had significantly lower total $\mathrm{IgE}$ levels $\left(35 \pm 21 \mathrm{kU} \cdot \mathrm{L}^{-1}\right)$ than sensitised rhinitic responders (table 3 ). There were no other remarkable differences in demographic and clinical data between the individual responder groups (table 3 ).

It is of particular interest to consider eNO levels in the nine corticosteroid-treated subjects (all latex-sensitised), of whom all but one $(87 \%)$ developed asthma $(n=3)$ or rhinitis alone $(n=5)$. As opposed to their frequent clinical responses, subjects

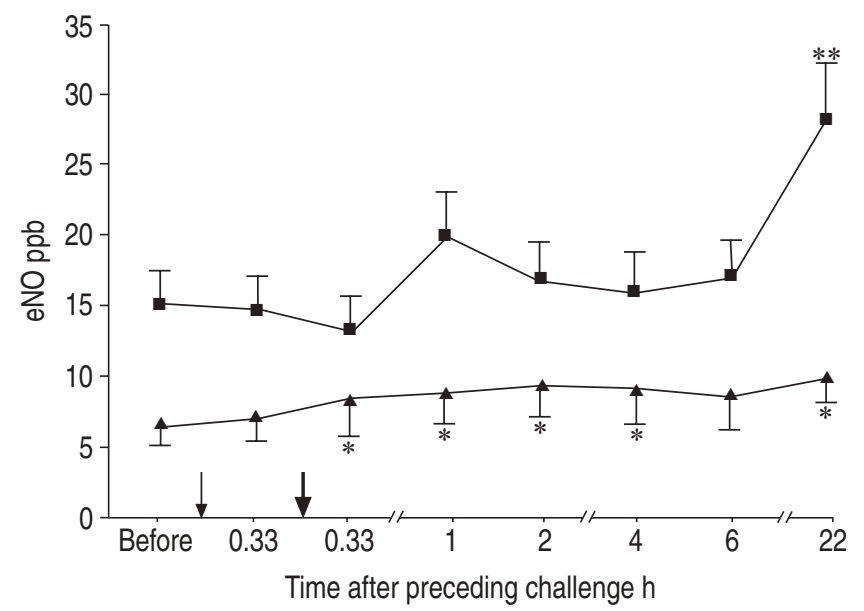

FIGURE 3. Time course of exhaled nitric oxide (eNO) concentration following placebo (thin vertical arrow) and latex (thick vertical arrow) challenge in smoking ( $\mathrm{n}=8)$ and nonsmoking $(\boldsymbol{\mathbf { a }} ; \mathrm{n}=5)$ asthmatic responders. Data are presented as mean \pm SEM. ${ }^{*}: p<0.05 ;{ }^{* *}: p<0.01$ versus respective baseline eNO 


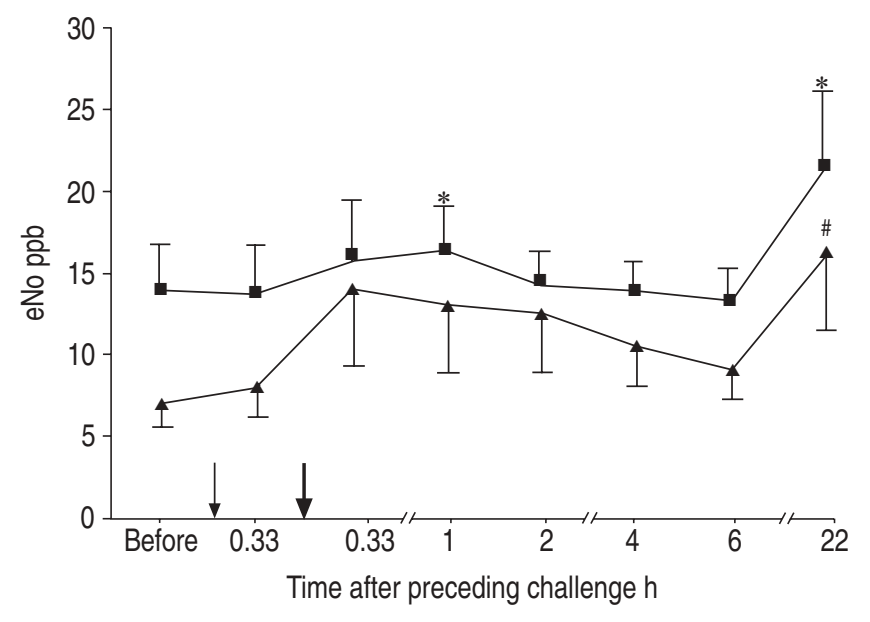

FIGURE 4. Time course of exhaled nitric oxide (eNO) concentration following placebo (thin vertical arrow) and latex (thick vertical arrow) challenge in smoking ( $\boldsymbol{\Delta}$ $\mathrm{n}=4)$ and nonsmoking $(\boldsymbol{\square} ; \mathrm{n}=12)$ latex-sensitised rhinitic only responders. Data are presented as mean \pm SEM. $\#: p=0.1 ;{ }^{*}: p<0.05$ versus respective baseline eNO.

on corticosteroid therapy revealed only borderline changes in eNO $22 \mathrm{~h}$ after latex challenge (table 2).

Conversely, the 22 latex-sensitised corticosteroid-naive healthcare workers, of whom 21 were responders, showed significant eNO increases irrespective of their smoking status $(10.9 \pm 3.1 \mathrm{ppb}$ in nonsmokers and $6.0 \pm 3.4 \mathrm{ppb}$ in smokers, a change in eNO concentration of $>50 \%$ in eight and five cases, respectively).

When the 22 sensitised corticosteroid-naive patients were subdivided into groups with and without a $>50 \%$ eNO increase, the first group exhibited a significantly greater $s R a w$ increase than the second $\left(1.39 \pm 0.26\right.$ versus $0.65 \pm 0.11 \mathrm{kPa} \cdot \mathrm{s}^{-1}$; $\mathrm{p}=0.02)$.

Considering the 31 latex-sensitised subjects, a positive correlation was also found between their percentage change in eNO $22 \mathrm{~h}$ after latex challenge and their maximum increases in sRaw (percentage from baseline) during the period $0-1 \mathrm{~h}$ after latex challenge (Spearman's $r=0.48 ; p<0.05$ ). Almost all of these subjects showed the maximum sRaw increase from baseline immediately following specific challenges. In this respect, no difference between smokers and nonsmokers was observed.

When considering the allergen-specific asthmatic response as the gold standard in occupational asthma, the sensitivity and specificity of elevated baseline eNO levels (cut-off $9.5 \mathrm{ppb}$ ) in nonsmokers were 100 and $61 \%$. Taking into account the obviously impaired eNO changes of corticosteroid-treated subjects, the sensitivity and specificity of change in eNO $22 \mathrm{~h}$ after challenge were calculated in corticosteroid-naive healthcare workers. The sensitivity and specificity of an eNO increase of $>50 \%$ after $22 \mathrm{~h}$ in this asthma-responding group were 70 and $79 \%$. The sensitivity and specifity of a change in eNO of $>50 \% 22 \mathrm{~h}$ after challenge with regard to both response types (asthma and/or rhinitis) were 56 and 100\%. (In comparison, taking the same gold standard, the sensitivity and specificity of latex-induced skin-prick test responses were 88 and 83\%).

\section{DISCUSSION}

The present results demonstrate that latex-sensitised but not nonsensitised healthcare workers exhibit a significant increase in eNO $22 \mathrm{~h}$ after occupational-type latex challenge compared to baseline levels. These findings extend those of challenge test results from studies performed by other groups with

TABLE 3 Changes in exhaled nitric oxide $(\triangle \mathrm{eNO})$ concentration and demographic data in individual responder groups and their various subgroups with respect to latex sensitisation

\begin{tabular}{|c|c|c|c|c|c|}
\hline & \multirow[t]{2}{*}{ Asthma ${ }^{\#}$} & \multicolumn{2}{|c|}{ Rhinitis alone } & \multicolumn{2}{|c|}{ Nonresponders } \\
\hline & & Sensitised & Nonsensitised & Sensitised & Nonsensitised \\
\hline Subjects $n$ & 13 & 16 & 4 & 2 & 10 \\
\hline \multicolumn{6}{|l|}{$\Delta$ eNO ppb } \\
\hline 20 min after placebo & $0.1 \pm 0.3$ & $0.1 \pm 0.5$ & $0.6 \pm 0.9$ & $0.4 \pm 0.4$ & $0.8 \pm 0.4$ \\
\hline 20 min after latex & $0.5 \pm 1.0$ & $3.1 \pm 1.5$ & $3.2 \pm 0.7$ & $0.1 \pm 0.9$ & $2.7 \pm 0.8$ \\
\hline $1 \mathrm{~h}$ after latex & $3.2 \pm 1.4$ & $3.3 \pm 1.3$ & $7.2 \pm 1.3$ & $1.4 \pm 1.2$ & $2.7 \pm 0.5$ \\
\hline $22 \mathrm{~h}$ after latex & $6.2 \pm 1.7^{\star}$ & $7.8 \pm 3.0$ & $1.7 \pm 2.0$ & $2.4 \pm 0.0$ & $0.5 \pm 0.3$ \\
\hline$\Delta \mathrm{eNO}$ of $>50 \% 22 \mathrm{~h}$ after latex & $9(69)^{*}$ & $6(38)$ & $1(25)$ & $0(0)$ & $0(0)$ \\
\hline \multicolumn{6}{|l|}{ Duration yrs } \\
\hline Latex glove exposure & $13.3 \pm 2.4$ & $11.3 \pm 2.5$ & $5.0 \pm 3.0$ & $6.5 \pm 1.5$ & $10.3 \pm 2.3$ \\
\hline Latex-induced symptoms ${ }^{+}$ & $4.7 \pm 1.1$ & $3.3 \pm 0.9$ & $3.1 \pm 1.5$ & $3.0 \pm 0.5$ & $6.8 \pm 2.0$ \\
\hline Atopy & $8(62)$ & $7(44)$ & $0(0)$ & $1(50)$ & $3(30)$ \\
\hline Total IgE kU· $\mathrm{L}^{-1}$ & $425 \pm 167$ & $312 \pm 123^{\star \star}$ & $35 \pm 21$ & $815 \pm 760$ & $269 \pm 163$ \\
\hline Latex-specific $\lg \mathrm{E} \mathbf{k U} \cdot \mathrm{L}^{-1}$ & $9.9 \pm 3.5$ & $3.4 \pm 1.3$ & 0.35 & $11.1 \pm 9.0$ & 0.35 \\
\hline BHR & $10(77)^{\star}$ & $6(38)$ & $1(25)$ & $1(50)$ & $3(30)$ \\
\hline
\end{tabular}

Data are presented as mean \pm SEM or $n(\%)$. Ig: immunoglobulin; BHR: bronchial hyperresponsiveness. ${ }^{*}$ : all sensitised; ${ }^{*}$ occupational allergenic; ${ }^{+}$: allergic. ${ }^{\star}$ : significantly different from corresponding reference subgroup (nonsensitised nonresponders for asthma group); ${ }^{\star \star}$ : significantly different from corresponding reference subgroup (nonsensitised rhinitis only responders; $p<0.05$ ). 
heterogeneous allergens. In 2003, LOPUHÄ̈ et al. [1] found, in asthma or rhinitis patients, similarly increased eNO levels 1 day after challenge with extracts from Dermatophagoides pteronyssinus. Corresponding findings were observed in asthmatic responders by KHARITONOV et al. [3] and Allmers et al. [6]. In 2002, PIIPARI et al. [21] described significant eNO elevation in patients with normal or slightly increased baseline eNO levels and a late bronchoconstrictive response to allergens and irritants but not in those with high baseline eNO levels. OватА et al. [22] found eNO increases in both responders and symptomatic nonresponders to western red cedar. Conversely, in 2001, TAN et al. [23], performing 16 latex allergen challenge tests, describe an eNO decrease until the sixth hour and only a small eNO rise up to the initial level after $24 \mathrm{~h}$. The reason for these discrepant findings is unclear, but different breathing patterns during eNO measurements, other methodological differences and/or substance-specific effects might have influenced the results.

Further analyses in the present subdivided groups of latexsensitised patients with regard to the location of the clinical response show no difference in eNO change between asthmatic and rhinitic groups. These results, confirming the respective findings of LOPUHA ̈̈ et al. [1], as well as the relationship of eNO changes with lung function in the present latex-sensitised subjects, correspond to the assumption that seemingly separate clinical disorders, namely allergic asthma and rhinitis, are manifestations of a unique entity with a common underlying pathophysiological process and only gradual differences in the involvement of the upper and lower airways [24-26]. The latter can be verified by stronger and, using categorical interpretation, more frequent methacholine hyperresponsiveness (77\% of the asthmatic and $37 \%$ of the rhinitic responders in the present study were hyperresponsive) and allergen-induced sRaw increases.

Owing to the high specificity of the allergen-induced increase in eNO of $>50 \%$ (none of the corticosteroid-naive nonresponders showed such a change), this measurement can supplement sensitive allergological testing, which produced positive results in $20 \%$ of nonresponders and $80 \%$ of rhinitic only and $100 \%$ of asthmatic responders. Therefore, eNO measurement before and 1 day after a work shift with latex allergen contact appears to be a reasonable diagnostic tool and an alternative to cumbersome laboratory challenge tests.

Furthermore, the significant and parallel latex allergeninduced increases in eNO and sRaw suggest that the diagnostic value of cross-shift eNO measurement should be evaluated as a screening method in healthcare workers, the majority of whom are frequently or chronically exposed to airborne latex allergens, with $3-17 \%$ becoming sensitised $[27,28]$. It would be particularly interesting to look at the predictive value of eNO changes, i.e. to follow them in the preclinical stages, when nasal and/or bronchial symptoms are still absent. It was recently shown that eNO increases precede sputum eosinophilia and lung function deterioration in asthmatics [29, 19].

The above-mentioned results indicate that eNO changes after allergen exposure (indicating acute allergic inflammatory responses) are of greater clinical relevance than baseline eNO levels, which did not clearly differentiate between sensitised and nonsensitised groups. The present authors consider their finding of an absence of an association between atopy status and eNO changes in the different response groups in atopics also to be an argument for this thesis.

Slight but significant eNO increases $1-5 \mathrm{~h}$ after latex allergen challenge were found in both sensitised and nonsensitised healthcare workers. Correspondingly, KHARITONOV et al. [3], in 1995, also described slight increases in eNO in immediate-type responders up to the fifth hour after allergen challenge. Since there is no evidence for diurnal variation of eNO concentration $[30,31]$, the present authors assume that these changes are due to non-immunological effects of particulate matter, i.e. of the allergen-carrying glove powder consisting of cornstarch. GRUNEWALD et al. [32] showed that inhalation of cornstarch glove powder leads to subclinical inflammation in the airways in previously unexposed subjects.

Previous investigations have already demonstrated suppressed eNO levels in smokers [33,34], which obviously limits the applicability of baseline eNO level as an inflammatory biomarker in these subjects. In the present study, however, it could be shown that smokers exhibit almost the same percentage of allergen-induced eNO increase as nonsmokers. This interesting result, reported for the first time, is of diagnostic value and presents eNO changes following allergen exposure as an inflammatory parameter independent of smoking status. It also pertains to the mechanism and regulation of the smoking-induced reduction in baseline eNO production. Smoking is associated with the upregulation of glutathione peroxidase in airway epithelial cells and alveolar macrophages [35] and activation of the transcription factor activator protein 1, which is involved in cytokine gene expression [33]. In 1998, Su et al. [34] found nonreversible nitric oxide synthase (NOS) (constitutive NOS) inhibition in endothelial cells by cigarette smoke extract, which seems to be due to an inhibitory action at the level of gene transcription. However, the present finding of a significant eNO increase following allergen exposure in smokers comparable to that of nonsmokers on a percentage basis represents indirect evidence that smoking does not affect inducible NOS (iNOS) expression.

In this respect, it is worth mentioning that patients on corticosteroid therapy, contrary to their clinical challenge test responses and corticosteroid-naive subjects, exhibited no eNO increase $22 \mathrm{~h}$ after latex challenge. It was recently shown that glucocorticoid receptor activation by corticosteroids can prevent transcription factors, such as nuclear factor- $\kappa \mathrm{B}$ and activator protein 1 , which regulate, among others, expression of the above-mentioned pro-inflammatory cytokine upregulating iNOS gene [36-38]. Accordingly, inhibition of nuclear factor- $\kappa \mathrm{B}$ results in inhibition of iNOS followed by a decrease in eNO. Although the present study did not address the molecular mechanisms through which eNO is regulated and influenced, the current data obviously verify the inhibitory effects of corticosteroids on allergen-induced eNO increase.

In conclusion, the present results suggest a diagnostic role for increased exhaled nitric oxide in latex allergen-exposed corticosteroid-naive healthcare workers as an early and easily obtainable marker of allergic airway inflammation and disorder. However, defining the exact role of exhaled nitric 
oxide as a predictor of upper and lower airway disease manifestation necessitates further investigations. Such studies would also be of interest with regard to people in other professions, such as bakers and isocyanate workers, who have a high risk of contracting occupational asthma.

\section{REFERENCES}

1 Lopuhaä CE, Koopmans JG, Jansen HM, van der Zee JS. Similar levels of nitric oxide in exhaled air in nonasthmatic rhinitis and asthma after bronchial allergen challenge. Allergy 2003; 58: 300-305.

2 Payne DN, Adcock IM, Wilson NM, Oates T, Scallan M, Bush A. Relationship between exhaled nitric oxide and mucosal eosinophilic inflammation in children with difficult asthma, after treatment with oral prednisolone. Am J Respir Crit Care Med 2001; 164: 1376-1381.

3 Kharitonov SA, O'Connor BJ, Evans DJ, Barnes PJ. Allergen-induced late asthmatic reactions are associated with elevation of exhaled nitric oxide. Am J Respir Crit Care Med 1995; 153: 454-457.

4 Gratziou C, Lignos M, Dassiou M, Roussos C. Influence of atopy on exhaled nitric oxide in patients with stable asthma and rhinitis. Eur Respir J 1999; 14: 897-901.

5 Thomassen MJ, Raychaudhuri B, Dweik RA, et al. Nitric oxide regulation of asthmatic airway inflammation with segmental allergen challenge. J Allergy Clin Immunol 1999; 104: 1174-1182.

6 Allmers H, Chen Z, Barbinova L, Marczynski B, Kirschmann V, Baur X. Challenge from methacholine, natural rubber latex, or 4,4-diphenylmethane-diisocyanate in workers with suspected sensitisation affects exhaled nitric oxide (change in exhaled NO levels after allergen challenges). Int Arch Occup Environ Health 2000; 73: 181-186.

7 Bates CA, Silkoff PE. Exhaled nitric oxide in asthma: from bench to bedside. J Allergy Clin Immunol 2003; 111: 256-262.

8 Henriksen AH, Sue-Chu M, Holmen TL, Langhammer A, Bjermer L. Exhaled and nasal NO levels in allergic rhinitis: relation to sensitisation, pollen season and bronchial hyperresponsiveness. Eur Respir J 1999; 13: 301-306.

9 Gratziou C, Rovina N, Lignos M, Vogiatzis I, Roussos C. Exhaled nitric oxide in seasonal allergic rhinitis: influence of pollen season and therapy. Clin Exp Allergy 2001; 31: 409-416.

10 Adisesh LA, Kharitonov SA, Yates DH, Snashell DC, Newman-Taylor AJ, Barnes PJ. Exhaled and nasal nitric oxide is increased in laboratory animal allergy. Clin Exp Allergy 1998; 28: 876-880.

11 Sippel JM, Holden WE, Tilles SA, et al. Exhaled nitric oxide levels correlate with measures of disease control in asthma. J Allergy Clin Immunol 2000; 106: 645-650.

12 Dupont LJ, Rochette F, Demedts MG, Verleden GM, Verleden GM. Exhaled nitric oxide correlates with airway hyperresponsiveness in steroid-naive patients with mild asthma. Am J Respir Crit Care Med 1998; 157: 894-898.

13 Deykin A, Belostotsky O, Hong C, Massaro AF, Lilly CM, Israel E. Exhaled nitric oxide following leukotriene $\mathrm{E}_{4}$ and methacholine inhalation in patients with asthma. Am J Respir Crit Care Med 2000; 162: 1685-1689.
14 Lim S, Jatakanon A, Meah S, Oates T, Chung KF, Barnes PJ. Relationship between exhaled nitric oxide and mucosal eosinophilic inflammation in mild to moderately severe asthma. Thorax 2000; 55: 184-188.

15 Chen Z, Posch A, Cremer R, Raulf-Heimsoth M, Baur X. Identification of hevein ( $\mathrm{Hev} v$ 6.02) in Hevea latex as a major cross-reacting allergen with avocado fruit in patients with latex allergy. J Allergy Clin Immunol 1998; 102: 476-481.

16 Baur X, Huber H, Degens P, Allmers H, Ammon J. Relation between occupational asthma case history, bronchial methacholine challenge, and specific test in patients with suspected occupational asthma. Am J Ind Med 1998; 33: 114-122.

17 Jäger D, Kleinhans D, Czuppon AB, Baur X. Latex-specific proteins causing immediate-type cutaneous, nasal, bronchial and systemic reactions. J Allergy Clin Immunol 1992; 89: 759-768.

18 Quanjer PH, Tammeling GJ, Cotes JE, Pedersen OF, Peslin R, Yernault JC. Lung volumes and forced ventilatory flows. Eur Respir J 1993; 6: Suppl. 16, 5-40.

19 Griese M, Koch M, Latzin P, Beck J. Asthma severity, recommended changes of inhaled therapy and exhaled nitric oxide in children: a prospective, blinded trial. Eur J Med Res 2000; 5: 334-340.

20 Kharitonov S, Alving K, Barnes PJ. Exhaled and nasal nitric oxide measurements: recommendations. Eur Respir J 1997 10: 1683-1693.

21 Piipari R, Piirila P, Keskinen H, Tuppurainen M, Sovijarvi A, Nordman H. Exhaled nitric oxide in specific challenge tests to assess occupational asthma. Eur Respir J 2002; 20: 1532-1537.

22 Obata H, Dittrick M, Chan H, Chan-Yeung M. Sputum eosinophils and exhaled nitric oxide during late asthmatic reactions in patients with western red cedar asthma. Eur Respir J 1999; 13: 489-495.

23 Tan K, Bruce C, Birkhead A, Thomas PS. Nasal and exhaled nitric oxide in response to occupational latex exposure. Allergy 2001; 56: 627-632.

24 Leynaert B, Neukirch F, Demoly P, Bousquet J. Epidemiologic evidence for asthma and rhinitis comorbidity. J Allergy Clin Immunol 2000; 106: 201-205.

25 Vignola AM, Chanez P, Godard P, Bousquet J. Relationships between rhinitis and asthma. Allergy 1998; 53: 833-839.

26 Togias A. Rhinitis and asthma: Evidence of respiratory system integration. J Allergy Clin Immunol 2003; 111: 1171-1183.

27 Vandenplas O, Delwiche J-P, Evrard G, et al. Prevalence of occupational asthma due to latex among hospital personnel. Am J Respir Crit Care Med 1995; 151: 54-60.

28 Baur X, Chen Z, Allmers H. Can a threshold limit value for natural rubber latex airborne allergens be defined? J Allergy Clin Immunol 1998; 101: 24-27.

29 Jatakanon A, Lim S, Barnes PJ. Changes in sputum eosinophils predict loss of asthma control. Am J Respir Crit Care Med 2000; 161: 64-72.

30 Kharitonov SA, Gonio F, Kelly C, Meah S, Barnes PJ. Reproducibility of exhaled nitric oxide measurements in healthy and asthmatic adults and children. Eur Respir J 2003; 21: 433-438. 
31 Lehtimake L, Turjanmaa V, Kankaanranta H, Saarelainen S, Hahtola P, Moilanen E. Increased bronchial nitric oxide production in patients with asthma measured with a novel method of different exhalation flow rates. Ann Med 2000; 32: 417-423.

32 Grunewald A, Eklund A, Katchar K, et al. Lung accumulations of eosinophil granulocytes after exposure to cornstarch glove powder. Eur Respir J 2003; 21: 646-651.

33 Kharitonov SA, Robbins RA, Yates DH, Keatings V, Barnes PJ. Acute and chronic effects of cigarette smoking on exhaled nitric oxide. Am J Respir Crit Care Med 1995; 152: 609-612.

$34 \mathrm{Su} \mathrm{Y,} \mathrm{Han} \mathrm{W,} \mathrm{Giraldo} \mathrm{C,} \mathrm{De} \mathrm{Li} \mathrm{Y,} \mathrm{Block} \mathrm{ER.} \mathrm{Effect} \mathrm{of}$ cigarette smoke extract on nitric oxide synthase in pulmonary artery endothelial cells. Am J Respir Cell Mol Biol 1998; 19: 819-825.

35 Comhair SA, Thomassen MJ, Erzurum SC. Differential induction of extracellular glutathione peroxidase and nitric oxide synthase- 2 in airways of healthy individuals exposed to $100 \% \mathrm{O}_{2}$ or cigarette smoke. Am J Respir Cell Moll Biol 2000; 23: 350-354.

36 Barnes PJ. Molecular mechanisms of corticosteroids in allergic diseases. Allergy 2001; 56: 928-936.

37 Barnes PJ, Adcock IM. Transcription factors and asthma. Eur Respir J 1998; 12: 221-234.

38 Raychaudhuri B, Dweik R, Connors MJ, et al. Nitric oxide blocks nuclear factor- $\kappa \mathrm{B}$ activation in alveolar macrophages. Am J Respir Cell Mol Biol 1999; 21: 311-316. 